\title{
Further results from a census based mortality study of fertiliser manufacturers
}

\author{
PATRICIA FRASER, ${ }^{1}$ CLAIR CHILVERS, ${ }^{2}$ M DAY,${ }^{3}$ P GOLDBLATT $^{4}$ \\ From the Epidemiological Monitoring Unit, ${ }^{1}$ London School of Hygiene and Tropical Medicine, London WCIE \\ $7 H T$, Section of Epidemiology, ${ }^{2}$ Institute of Cancer Research, Sutton, Surrey SM2 5NG, Medical Statistics \\ Division, ${ }^{3}$ Office of Population Censuses and Surveys, London WC2B 6JP, and Social Statistics Research Unit, ${ }^{4}$ \\ The City University, London ECIV OHB, UK
}

ABSTRACT The results of a further follow up of two cohorts of men identified as manufacturers of fertilisers in the 1961 and 1971 censuses of England and Wales are reported. Both cohorts have now? been followed up until 1985 through the National Health Service Central Register. In the 1961 cohorț the previous findings are replicated-low mortality from all causes, all cancers, and all circulatory diseases, and no evidence of dose response relation nor excess mortality from cancer at any site. In theo 1971 cohort there remain more deaths from cancer than expected but none of the observed deaths from individual cancers differs significantly from expectation by comparison with national mortality rates or rates for other employed men. Evidence of an association between cancer mortality and frequency of exposure to nitrate containing dust is strengthened in the reanalysis of the 1971 cohor after longer follow up, but a negative trend, significant for digestive organ cancers, is observed in the analysis by product type in which manufacturers of straight nitrogen and compound fertilisers mightso have been expected to be most at risk. Failure to find specifically any excess mortality from gastgice cancer and the contradictory dose response relations, weigh against the notion that the nofin significant excesses of cancers in the 1971 cohort are related to nitrate exposure.

In 1982 we reported the results of a census based mortality study of fertiliser manufacturers. ${ }^{1}$ The study was designed to investigate whether exposure to nitrate containing dust during fertiliser manufacture was associated with an excess of deaths from cancer in general or specifically from cancers of the digestive tract, liver, lung, and bladder. The study was based on data abstracted from census schedules by the Office of Population Censuses and Surveys (OPCS)occupational characteristics recorded by fertiliser workers at the 1961 and 1971 censuses of England and Wales being related to subsequent mortality ascertained through the National Health Service Central Register (NHSCR). The 1961 cohort, followed up until 1978, showed no evidence of dose response. There were, however, more deaths from cancer than expected in the 1971 cohort during 1971-7 due mainly to an excess of cancers of the lung and digestive tract. Though the numbers for comparison were small, there was weak evidence of an association between cancer mortality and the frequency of exposure to nitrate containing dust in this cohort. Whereas neither the

Accepted 4 January 1988

(C) Crown copyright excess cancer mortality nor the gradient in risk achieved statistical significance, the findings were sufficiently interesting to warrant further study when $\overrightarrow{\overrightarrow{0}}$ substantially more deaths had accrued.

\section{Methods}

The study design has been described in detail else? where. ${ }^{1}$ Both cohorts of fertiliser manufacturers have? now been followed up to the end of 1985 with continuous notification of deaths to OPCS by? NHSCR. Their mortality from malignant neoplasms

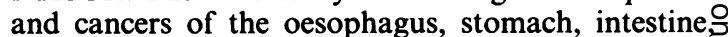
rectum, liver, lung, and bladder is compared here with $\rightarrow$ the expected numbers of deaths by cause, derived from age and calendar period specific male death rates forn England and Wales. Mortality from all causes and from other major causes of death is also examined The numbers of deaths observed in men in the $1971 \mathrm{k}$ cohort who were in employment at the time of the census are also compared with those expected on theo basis of unpublished death rates for employed men in the OPCS Longitudinal Study. ${ }^{2}$ The mortality data in ${ }^{\text {? }}$ both cohorts are subdivided by frequency of dust 
exposure and type of product to look for evidence of dose response relations.

All analyses were carried out at OPCS to preserve confidentiality, using their mortality analysis system (unpublished). No information about identified individuals left OPCS at any stage. All significance tests of the ratios of observed to expected deaths were two sided and based on the Poisson distribution. ${ }^{3} \mathrm{~A} \chi^{2}$ test based on that of Mantel ${ }^{4}$ was used to test for a linear trend across each exposure category, with adjustment for the other exposure category in each instance. Because numbers were small, linear logistic models were also fitted to confirm the results.

\section{Results}

The 1961 cohort consisted of 862 men classified as fertiliser manufacturers and traced in the NHSCR. At the time of the census, $97 \%$ were occupied. Between the census and the end of 1985, 372 deaths had been notified in the fertiliser workers whereas $448 \cdot 3$ would have been expected on the basis of national mortality rates (table 1$)$. The observed $(\mathrm{O})$ to expected $(\mathrm{E})$ ratio of 0.83 represents a significant deficit $(p<0.05)$. Fewer deaths than expected from circulatory diseases, especially ischaemic heart disease, are major contributors to the overall deficit. The observed to expected ratio for all cancers is also 0.83 but, based on only 97 deaths, falls just short of statistical significance $(p=0.07)$. The observed to expected ratios for bronchitis and lung cancer are close to unity. All the other cause specific ratios, except that for intestinal cancer, are low but the $95 \%$ confidence limits are wide and none of the observed values differs significantly from expectation.

The 1971 cohort consisted of 652 fertiliser manufacturers. In this cohort 136 deaths occurred between the
Table 2 Mortality in fertiliser workers in employment at census by comparison with employed men: 1971 cohort (1971-83)

\begin{tabular}{|c|c|c|c|c|}
\hline $\begin{array}{l}\text { Cause of death } \\
\text { (8th rev } \\
\text { ICD code) }\end{array}$ & $\begin{array}{l}\text { Observed } \\
\text { deaths }(O)\end{array}$ & $\begin{array}{l}\text { Expected } \\
\text { deaths }(E)\end{array}$ & $O / E$ & $\begin{array}{l}95 \% \\
\text { Confidence } \\
\text { interval }\end{array}$ \\
\hline $\begin{array}{l}\text { All causes }(000-999) \\
\text { All cancers }(140-209) \text { : } \\
\text { Lung cancer (162) } \\
\text { Digestive organ }\end{array}$ & $\begin{array}{l}96 \\
38 \\
18\end{array}$ & $\begin{array}{l}96 \cdot 8 \\
29.8 \\
12 \cdot 6\end{array}$ & $\begin{array}{l}0.99 \\
1.28 \\
1.43\end{array}$ & $\begin{array}{l}0.80-1.21 \\
0.90-1.75 \\
0.85-2.26\end{array}$ \\
\hline $\begin{array}{l}\text { cancers }(150-6) \\
\text { Circulatory diseases }\end{array}$ & 10 & $7 \cdot 5$ & $1 \cdot 34$ & $0.64-2.46$ \\
\hline $\begin{array}{l}(390-458) \text { : } \\
\text { Ischaemic heart }\end{array}$ & 43 & $50 \cdot 2$ & 0.86 & $0 \cdot 62-1 \cdot 15$ \\
\hline $\begin{array}{r}\text { disease }(410-414) \\
\text { Bronchitis }(490-493)\end{array}$ & $\begin{array}{r}36 \\
5\end{array}$ & $\begin{array}{r}36 \cdot 8 \\
3 \cdot 7\end{array}$ & $\begin{array}{l}0.98 \\
1.35\end{array}$ & $\begin{array}{l}0.69-1 \cdot 35 \\
0.44-3 \cdot 15\end{array}$ \\
\hline
\end{tabular}

census in 1971 and the end of 1985 , whereas 145.5 would have been expected on the basis of national rates. The ratio, 0.93 , represents a non-significant deficit. There are in fact no statistically significant departures from expectation in the 1971 cohort in table 1 . As in the previous analysis' there remain more deaths from cancer than expected but the observed to expected ratios both for all cancers and for individual sites are not significantly increased. When the numbers of deaths from cancers of the digestive organs (oesophagus, stomach, intestine, rectum, and liver) are aggregated, the ratio of observed deaths, 13, to expected deaths, 10.4 , is 1.25 which is still not significantly increased since unity lies well within its $95 \%$ confidence interval $(0 \cdot 67-2 \cdot 14)$.

Of the fertiliser workers in the 1971 cohort, $96 \%$ were in employment the week before the census. When death rates from 1971 to 1983 for employed men in the OPCS Longitudinal Study are used as the basis for calculating the expected deaths for comparison with observed deaths to the end of 1983 , the fertiliser workers' mortality is less favourable (table 2) than

Table 1 Mortality in fertiliser manufacturers by comparison with all men

\begin{tabular}{|c|c|c|c|c|c|c|c|c|}
\hline \multirow[b]{2}{*}{$\begin{array}{l}\text { Cause of death } \\
\text { ( } 8 t h \text { rev } \\
\text { ICD code) }\end{array}$} & \multicolumn{4}{|c|}{1961 cohort (1961-85) } & \multicolumn{4}{|c|}{1971 cohort $(1971-85)$} \\
\hline & $\begin{array}{l}\text { Observed } \\
\text { deaths }(O)\end{array}$ & $\begin{array}{l}\text { Expected } \\
\text { deaths (E) }\end{array}$ & $O / E$ & $\begin{array}{l}95 \% \\
\text { Confidence } \\
\text { interval }\end{array}$ & $\begin{array}{l}\text { Observed } \\
\text { deaths (O) }\end{array}$ & $\begin{array}{l}\text { Expected } \\
\text { deaths }(E)\end{array}$ & $O / E$ & $\begin{array}{l}95 \% \\
\text { Confidence } \\
\text { interval }\end{array}$ \\
\hline $\begin{array}{l}\text { All causes }(000-999) \\
\text { All cancers (140-209): } \\
\text { Oesophageal cancer (150) } \\
\text { Gastric cancer }(151) \\
\text { Intestinal cancer }(152-3) \\
\text { Rectal cancer }(154) \\
\text { Liver cancer }(155-6) \\
\text { Lung cancer (162) } \\
\text { Bladder cancer (188) } \\
\text { Circulatory diseases (390-458): } \\
\text { Ischaemic heart disease }(410-414) \\
\text { Cerebrovascular disease }(430-438) \\
\text { Bronchitis (490-493) } \\
\text { Accidents (800-999) } \\
\text { Others }\end{array}$ & $\begin{array}{r}372 \\
97 \\
1 \\
8 \\
10 \\
4 \\
1 \\
48 \\
4 \\
182 \\
118 \\
36 \\
29 \\
7 \\
57\end{array}$ & $\begin{array}{r}448 \cdot 3 \\
117.0 \\
3 \cdot 4 \\
12 \cdot 5 \\
7.4 \\
5 \cdot 3 \\
1.6 \\
49 \cdot 8 \\
4 \cdot 8 \\
225 \cdot 1 \\
145 \cdot 6 \\
41.9 \\
29.7 \\
11.4 \\
65 \cdot 0\end{array}$ & $\begin{array}{l}0.83^{*} \\
0.83 \\
0.29 \\
0.64 \\
1.35 \\
0.75 \\
0.62 \\
0.96 \\
0.83 \\
0.81^{*} \\
0.81^{*} \\
0.86 \\
0.98 \\
0.61 \\
0.88\end{array}$ & $\begin{array}{l}0.75-0.92 \\
0.67-1.01 \\
0.01-1.64 \\
0.28-1.27 \\
0.65-2.48 \\
0.20-1.92 \\
0.02-3.47 \\
0.71-1.28 \\
0.23-2.13 \\
0.70-0.94 \\
0.67-0.98 \\
0.60-1.19 \\
0.66-1.40 \\
0.25-1.27 \\
0.66-1.14\end{array}$ & $\begin{array}{r}136 \\
49 \\
2 \\
4 \\
3 \\
3 \\
1 \\
24 \\
0 \\
65 \\
53 \\
7 \\
6 \\
3 \\
13\end{array}$ & $\begin{array}{r}145 \cdot 5 \\
41 \cdot 5 \\
1.4 \\
3.9 \\
2.6 \\
1.9 \\
0.6 \\
17 \cdot 5 \\
1.5 \\
74 \cdot 3 \\
52.8 \\
11 \cdot 2 \\
6 \cdot 8 \\
4.6 \\
18.3\end{array}$ & $\begin{array}{r}0.93 \\
1.18 \\
1.44 \\
1.02 \\
1.14 \\
1.62 \\
1.64 \\
1.37 \\
0 \\
0.88 \\
1.00 \\
0.63 \\
0.89 \\
0.65 \\
0.71\end{array}$ & $\begin{array}{l}0.78-1 \cdot 11 \\
0.87-1.56 \\
0.17-5.20 \\
0.28-2.62 \\
0.24-3.34 \\
0.33-4.73 \\
0.04-9.13 \\
0.88-2.04 \\
0.00-2.46 \\
0.68-1.12 \\
0.75-1.31 \\
0.25-1.29 \\
0.33-1.93 \\
0.13-1.91 \\
0.38-1.21\end{array}$ \\
\hline
\end{tabular}

*p $<0.05$. 
Table 3 Mortality in fertiliser workers by frequency of dust exposure: 1961 cohort (1961-85) and 1971 cohort (1971-85) 'C

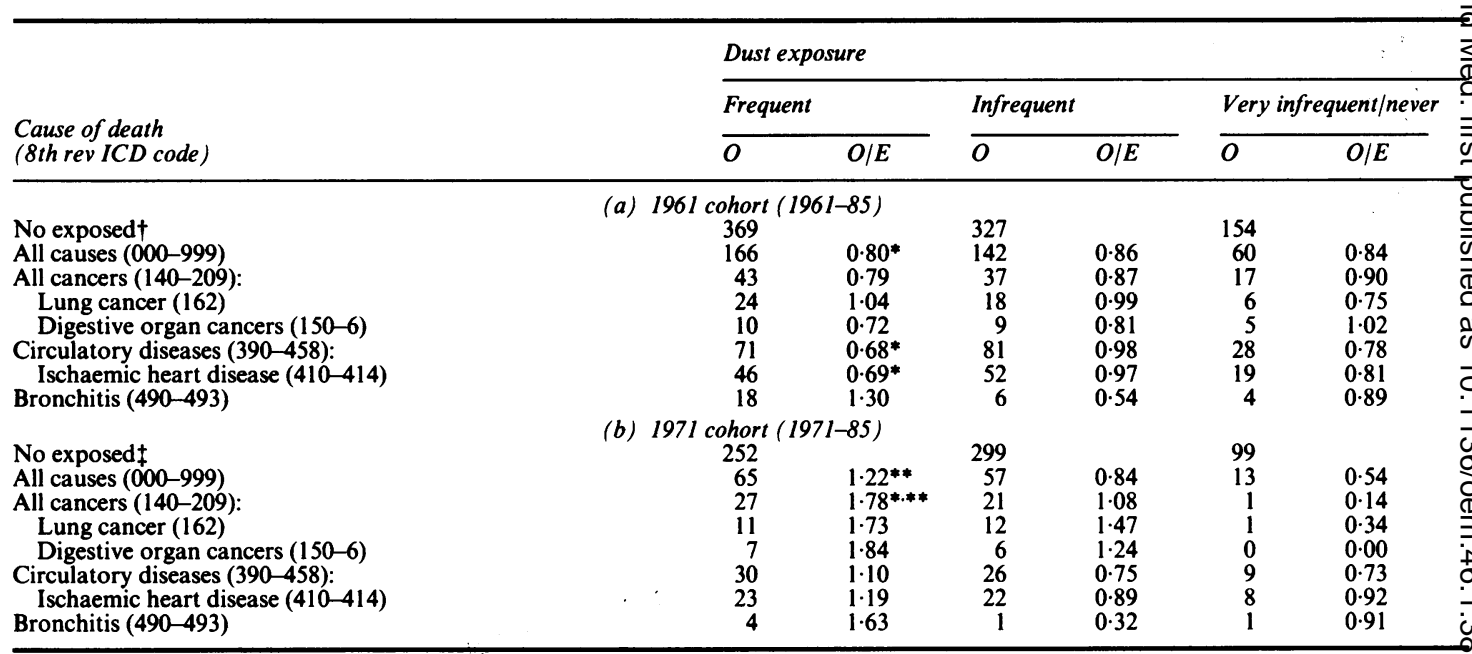

$* \mathrm{p}<0.05 ; * *$ trend test, $\mathrm{p}<0.05$.

†Twelve workers could not be classified.

$\ddagger$ Two workers could not be classified.

when the comparison is made with the male population of England and Wales in general (table 1). The deficit in all cause mortality is reduced by $6 \%$ and the non-significant excesses of all cancers and cancers of the lung and digestive organs are more apparent when compared with other employed men. Excess mortality from bronchitis is also seen in table 2.

In table 3 mortality from selected causes of death has been examined in three dust exposure categories. In the 1961 cohort (table 3a) there are no significant gradients in risk with increasing exposure nor excess mortality from any cause. On the contrary, there are significant deficits of deaths from all causes, circulatory diseases, and ischaemic heart disease in the most frequently exposed group of men. Table $3 \mathrm{~b}$, however, shows a significant excess of deaths from cancer in the most frequently exposed men in the 1971 cohort and a significant linear trend both for all cancers and all cause mortality. Lung cancer and

cancers of the digestive organs both contribute to the significant trend in risk with increasing frequency ow exposure to nitrate containing dust for all cancers $>$ although neither trend is individually statisticallys significant. In both cohorts men exposed frequentlygos dust have the highest mortality from bronchitis.

In table 4 the 1971 cohort has been subdivide according to the type of product manufactured in order to investigate further the trends in table $3 \mathrm{~b}$ Ninety three per cent $(608 / 652)$ of workers could beD classified by the type of fertiliser manufacturec (straight nitrogen plus compound fertilisers? compound fertilisers only, or other fertilisers and manures). More than $75 \%$ of the cohort worked in companies producing straight nitrogen and compound fertilisers. Thirteen per cent produced compound fertilisers only and $5 \%$ other fertilisers and manures. Across the groups there is a significants negative association between mortality from digestive

Table 4 Mortality in fertiliser manufacturers by product: 1971 cohort (1971-85)

\begin{tabular}{|c|c|c|c|c|c|c|}
\hline \multirow[b]{2}{*}{ Cause of death (8th rev ICD code) } & \multicolumn{2}{|c|}{$\begin{array}{l}\text { Straight nitrogen plus } \\
\text { compound fertilisers }\end{array}$} & \multicolumn{2}{|c|}{ Compound fertilisers } & \multicolumn{2}{|c|}{$\begin{array}{l}\text { Other fertilisers } \\
\text { and manures }\end{array}$} \\
\hline & $O$ & $O / E$ & $O$ & $O / E$ & $O$ & $O / E$ \\
\hline $\begin{array}{l}\text { No exposed } \dagger \\
\text { All causes }(000-999) \\
\text { All cancers }(140-209) \text { : } \\
\text { Lung cancer }(162) \\
\text { Digestive organ cancers }(150-6) \\
\text { Circulatory diseases }(390-458) \text { : } \\
\text { Ischaemic heart disease (410-414) } \\
\text { Bronchitis }(490-493)\end{array}$ & $\begin{array}{r}491 \\
98 \\
34 \\
18 \\
8 \\
51 \\
42 \\
3\end{array}$ & $\begin{array}{l}0.92 \\
1.11 \\
1.40 \\
1.05^{* *} \\
0.94 \\
1.08 \\
0.62\end{array}$ & $\begin{array}{r}86 \\
20 \\
8 \\
2 \\
2 \\
7 \\
6 \\
2\end{array}$ & $\begin{array}{l}1.09 \\
1.53 \\
0.92 \\
1.53 \\
0.75 \\
0.90 \\
2.34\end{array}$ & $\begin{array}{r}31 \\
7 \\
4 \\
1 \\
3 \\
1 \\
1 \\
1\end{array}$ & $\begin{array}{l}0.81 \\
1.65 \\
0.98 \\
4.91 \\
0.23 \\
0.33 \\
2.27\end{array}$ \\
\hline
\end{tabular}

$* \mathrm{p}<0.05 ;{ }^{* *}$ trend test, $\mathrm{p}<0.05$.

+ Forty four workers could not be classified. 
organ cancers and exposure to nitrate and significant excess mortality in the small group of workers least exposed to nitrate. In a similar analysis of the 1961 cohort there were no significant findings but only $75 \%$ $(646 / 862)$ of the cohort could be classified according to the type of fertiliser manufactured. Fifty five per cent of the 1961 cohort worked in companies manufacturing both straight nitrogen and compound fertilisers and only about $10 \%$ of workers were assigned to each of the other two product categories.

\section{Discussion}

There are some minor discrepancies between the results presented in our earlier paper and those presented here. One woman was inadvertantly included in the earlier analysis and two men not previously traced in the 1971 cohort are now included. A few coding errors have also been corrected. The effects of these changes had they been applied in our earlier analysis are small and do not affect our previous conclusions.

The findings in the 1961 cohort, with a $60 \%$ increase in the number of deaths over the further seven years of follow up, replicate those in the previous analysis. ${ }^{1}$ Low mortality from all causes, all cancers, and all circulatory diseases were features of that analysis and there was no evidence of a dose response relation nor excess mortality from cancer at any site.

The further eight years of follow up in the 1971 cohort increased the number of deaths more than threefold from 43 in 1977 to 136 by the end of 1985. Again the comparison of this substantially larger number of deaths with national death rates replicates the previous findings in that none of the observed deaths from individual cancers or broader categories of disease examined differs significantly from expectation.

Only fertiliser manufacturers reporting an occupation at census were included in these cohorts; the permanently sick and men otherwise out of work who did not report an occupation at census were not eligible for the study. Therefore death rates among employed men in the OPCS Longitudinal Study, available for 1971-83, provide a more appropriate standard for comparison in the 1971 cohort than the national rates. This analysis shows that overall mortality in the fertiliser workers, with an observed to expected ratio of 0.99 , is typical of employed men. The non-significant excesses of bronchitis, all cancers, and cancers of the lung and digestive organs in particular are enhanced in the comparisons with other employed men.

Our classifications of fertiliser workers by frequency of exposure to nitrate containing dust and by the type of product manufactured were intended to provide two gradients of potential exposure to nitrate. Use of these exposure measures is supported by the finding of Al-Dabbagh et al that men exposed to nitrate during fertiliser manufacture have substantially raised concentrations of nitrate in their saliva compared both with controls within the industry and with men in the general population and resident nearby. ${ }^{5}$ Although evidence of an association between cancer mortality and frequency of exposure to nitrate containing dust is strengthened in the reanalysis of the 1971 cohort after longer follow up (table 3b), the association is not supported in table 4 where manufacturers of straight nitrogen plus compound fertilisers might have been expected to be most at risk. It should be pointed out, however, that the numbers of deaths expected for individual cancer sites in table $\mathbf{4}$ are small, particularly when cross classified by dust exposure in addition to product type.

The significant excess cancer mortality in the most frequently exposed men in table $3 \mathrm{~b}$ is largely attributable to excesses of cancers of the lung and digestive organs. A small increase in mortality from lung cancer in heavily exposed nitrate fertiliser workers who had been employed for 10 or more years and were observed for 20 or more years after first exposure was reported by Al-Dabbagh et al. ${ }^{5}$ Whereas the findings in that study and our 1971 cohort are consistent with the possibility that nitrates in the ambient atmosphere might increase the risk of lung cancer, in neither study were data available that would enable the effects of smoking to be taken into account. There is no evidence from the study of Al-Dabbagh et al to suggest that cancers of the digestive organs (oesophagus and stomach) result from occupational exposure to nitrate.

Of all cancers, nitrate has been most strongly implicated in the aetiology of gastric cancer ${ }^{6}$ but we observed only four deaths from this cancer in the 1971 cohort against 3.9 expected. Failure to find any excess of gastric cancer and our contradictory trends in tables $3 \mathrm{~b}$ and 4 weigh against the notion that the nonsignificant excesses of cancers in the 1971 cohort are related to nitrate exposure. Gastric cancer, lung cancer, and bronchitis, however, have all been linked to dust exposure in various contexts that suggest that physical, as well as chemical, irritants may pose a hazard. ${ }^{7-11}$ Thus one possible explanation for the lack of concordance in the dose response relations in the 1971 cohort is that dust per se rather than the nitrate content is a risk factor.

If this hypothesis is correct it is not obvious why similar or even steeper gradients of increasing risk with increasing frequency of dust exposure are not seen in the 1961 cohort. The assessment of the frequency of dust exposure in each job was carried out in 1980 by the occupational hygienist of a major fertiliser manufacturing company. Could it be that some of the 
jobs classified as relatively dust free at that time involved more frequent exposure to ambient dust in 1961 when conditions were generally less good? If this were the case our classification of jobs by frequency of dust exposure may be inappropriate for the 1961 cohort. Nevertheless this would not explain the difference in overall mortality between the two cohorts.

We have established in this analysis that a similar proportion of each cohort was in employment at census and, in our previous analysis, ${ }^{1}$ that the two cohorts were distributed similarly by region and social class, and that the tracing rates, $96 \%$ and $98 \%$ respectively, were satisfactory. Industrial hygiene has improved over time and we are not aware of any changes in manufacture of fertilisers which could have placed the 1971 cohort at a disadvantage by comparison with the earlier cohort. Thus we are unable to offer an explanation for the less favourable level of mortality in the more recent cohort.

We gratefully acknowledge support from the Medical Research Council (PF, CC, and PG) and the Cancer Research Campaign (CC). The study would not have been possible without the help of staff of the NHSCR at Southport, the Medical Statistics Division at OPCS and the Longitudinal Study Management Unit.

\section{References}

1 Fraser P, Chilvers C, Goldblatt P. Census-based mortality study of fertiliser manufacturers. Br J Ind Med 1982;39:323-9.

2 Fox AJ, Goldblatt PO. Longitudinal study: socio-demograph mortality differentials, 1971-75. London: HMSO, 198 हे (LS No 1.)

3 Bailar JC, Ederer F. Significance factors for the ratio of a Poisso variable to its expectation. Biometrics 1964;20:639-43.

4 Mantel N. Chi-square tests with one degree of freedom: extension of the Mantel-Haenszel procedure. Journal of the American Statistical Association 1963;58:690-700.

5 Al-Dabbagh S, Forman D, Bryson D, Stratton I, Doll R. Mortality of nitrate fertiliser workers. Br J Ind Med $198 \dot{6 \dot{3}}$ 43:507-15.

6 Mirvish SS. The aetiology of gastric cancer, intragastri nitrosamide formation and other theories. JNCI 1983;7

$631-47$.
Office of Population Censuses and Surveys. Occupational mortali $\bar{\phi}$ 1970-72. London: HMSO, 1978. [DS No 1.)

8 Jacobson M. Dust exposure, lung diseases and coalminer 50 mortality. Edinburgh: University of Edinburgh, 1976. (Phमु thesis.)

9 McDonald JC, Liddell FDK, Gibbs GW, Eyssen GE, McDonale AD. Dust exposure and mortality in chrysotile mining, 1910-75Br J Ind Med 1980;37:11-24.

10 Fox AJ, Goldblatt P, Kinlen LJ. A study of the mortality Cornish tin miners. Br J Ind Med 1981;38:378-80.

11 Anon. Occupation and bronchitis. Lancet 1980;i:235-6.

\section{Destruction of manuscripts}

From 1 July 1985 articles submitted for publication will not be returned. Authors whose papers are rejected will be advised of the decision and the manuscripts will be kept under security for three months to deal with any inquiries and then destroyed. 